\title{
Coronary arterial anatomy in bicuspid aortic valve Necropsy study of 100 hearts
}

\author{
PAUL K LERER,* WILLIAM D EDWARDS \\ From the Department of Pathology and Anatomy and from the Mayo Medical School, \\ Mayo Clinic and Foundation, Rochester, Minnesota, USA
}

SUMMARY In a necropsy study, the conjoined cusps of 50 congenitally and 50 acquired bicuspid aortic valves most commonly involved the right and left aortic cusps. In hearts with congenitally bicuspid aortic valves, the left coronary ostium arose at or above the aortic sinotubular junction in 44 per cent, whereas the incidence for the left coronary ostium in the acquired group was 20 per cent and that for the right coronary ostium in both groups was less than 20 per cent. In hearts with congenitally bicuspid aortic valves, the incidence of left coronary dominance $(26 \%)$ was higher than in normal hearts. In hearts with apparently acquired bicuspid aortic valves, this incidence was also higher than normal, possibly because of acquired fusion of atypical congenitally bicuspid valves in some cases. In both types of aortic valve disease, the length of the left main coronary artery was similar; this length, however, was significantly shorter in hearts with left coronary dominance than in those with right or shared dominance.

In patients with congenitally bicuspid aortic valves, the reported incidence of left coronary dominance varies greatly (25 to $57 \%) .{ }^{1-5}$ Though not yet accurately established, this incidence is certainly higher than that in the normal population (10 to $12 \%){ }^{2}{ }^{4}$ Likewise, a higher than expected incidence of short left main coronary artery has been reported in patients with either a bicuspid aortic valve, left coronary dominance, or both ${ }^{346}$; it is not yet clear whether a short left main coronary artery is truly dependent on left coronary dominance or the bicuspid state of the aortic valve. In patients with bicuspid aortic valves, coronary ostial positions with respect to the aortic sinotubular junction, have not been well documented. Knowledge of variation, however, in the site of origin and length of the left main coronary artery, and of the pattern of coronary arterial distribution has practical application in the interpretation of coronary arteriography and in avoidance of selective perfusion of one major division of the left main artery, either at angiography or at operation. ${ }^{3-8}$

With the above considerations in mind, the following study was undertaken to determine coronary arterial variations in 100 necropsy hearts with biscupid aortic valves. In addition, with the

Present address: Department of Internal Medicine, Boston City Hospital, Boston, Massachusetts 02118, USA.

Received for publication 1 July 1980 hypothesis that a short left main coronary artery may be the result embryologically of partial incorporation of this artery into the left aortic sinus, the incidence of aortic origin of the conus coronary artery was also determined. If the proximal right coronary artery also underwent a similar embryological incorporation into the right aortic sinus, then a higher than normal incidence of aortic origin of the conus artery would be expected in those cases with a short left main coronary artery.

\section{Subjects and methods}

From the Tissue Registry of the Mayo Clinic, 50 hearts with congenitally bicuspid aortic valves were selected, as were 50 hearts with acquired bicuspid aortic valves. Valves which were so calcified and deformed so as to preclude distinction between the congenital and the acquired bicuspid state were excluded. In addition, this study does not include hearts with additional congenital anomalies, such as aortic coarctation, persistent ductus arteriosus, or ventricular septal defect.

By gross examination, bicuspid aortic valves were considered congenital if they contained a conjoined cusp and were considered acquired if they showed fusion of a true commissure. ${ }^{9-13}$ The raphe was generally shallow, originating below the aortic sinotubular junction and terminating well below the 
cuspid line of closure. In contrast, a fused commissure originated at the level of the sinotubular junction and usually maintained a level similar to that of the closing edge of the remainder of the valve. Even though the two fused cusps were often calcified, remnants of these involved cusps could usually be identified in the region of fusion. (The aortic sinotubular junction is a ridge which separates the aortic sinuses, below, from the tubular ascending aorta, above, and also generally represents the highest insertion site of the true aortic valve commissures.)

Aortic valves in the congenital group had obvious raphes and were readily classified as congenitally bicuspid. Admittedly, however, evaluation of the aetiology of the bicuspid state in the acquired group was sometimes quite difficult (even though the much deformed and calcified valves of end-stage aortic stenosis had been excluded). Though all valves in the acquired group had obvious fusion of two cusps along variable lengths, the commissural region near the aortic wall was difficult to evaluate in some cases and may well have initially represented a short, or partial, congenital raphe (so-called atypical or forme fruste congenitally bicuspid aortic valve).

The nature of the acquired fusion in the majority of cases was rheumatic, as determined by the gross appearance of the aortic valve and by concomitant rheumatic mitral valvular disease. In some cases, however, the aortic valves appeared to be involved by either degenerative or non-rheumatic inflammatory processes; frequently, in these cases, the mitral valve was either normal or involved by nonrheumatic disease (for example floppy mitral valve).

The right and left coronary ostia were evaluated with respect to their distance from the sinotubular junction (Fig. 1A). Previous excision of portions of this junction precluded this measurement in six right and nine left coronary ostia in both the congenital group and the acquired group. In addition, the conus coronary artery was evaluated with respect to its aortic or right coronary arterial origin; because of previous dissection, this determination was not possible in five cases from the congenital group.

Coronary arterial dominance was determined after careful dissection of the major epicardial arteries at the crux of the heart. (The crux is a cross-shaped region along the inferior cardiac surface representing the intersection of the atrioventricular sulcus with the interatrial and the inferior interventricular sulci.) If the right coronary artery crossed the crux and gave rise to the posterior descending branch, then right coronary dominance pertained; if the circumflex coronary artery, then left coronary dominance was defined; and if both the right and circumflex arteries gave rise to posterior descending branches (usually of similar size), then shared dominance or so-called balanced circulation was present. ${ }^{1-3} 14$

The length of the left main coronary artery was measured from the outer aortic wall to the site of bifurcation into anterior descending and circumflex branches (Fig. 1B). In 14 instances of trifurcation (10 in the congenital group and four in the acquired group), the site of division into anterior descending and circumflex branches was estimated (Fig. 1C).

\section{Results}

In both groups, there were 41 men and nine women. In the congenital group the age range was 15 to 86 years (mean 60 ), and in the acquired group it was 39 to 88 years (mean 65). Other than the presence of a bicuspid aortic valve, no other variable in this

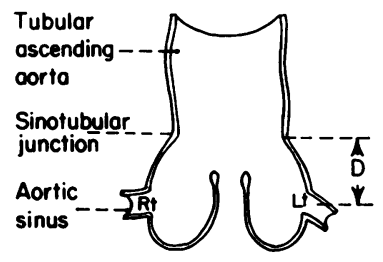

A

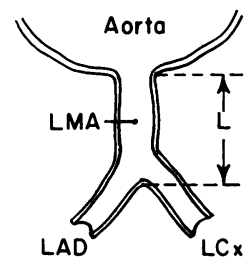

B

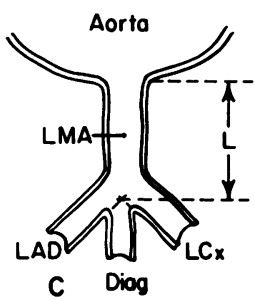

C Diog

Fig. 1 Cardiac measurements. (A) Schematic diagram of longitudinal section through ascending aorta and right $(R t)$ and left $(L t)$ coronary ostia. Distance $(D)$ is measured from aortic sinotubular junction to centre of each coronary ostium. ( $B$ and $C$ ) Schematic diagrams of cross-section through ascending aorta and left coronary artery. In $(B)$, length $(L)$ of left main coronary artery $(L M A)$ is from outer aortic wall to site of bifurcation into left anterior descending ( $L A D)$ and left circumflex ( $L C x$ ) branches. In $C$, length of $L M A$ when trifurcation occurs. Diag, diagonal branch. 
study was dependent upon the sex of the patient. Only the extent of aortic valvular calcification varied with age; generally, calcification increased with increasing age.

\section{BICUSPID AORTIC VALVES}

\section{CONGENITAL}

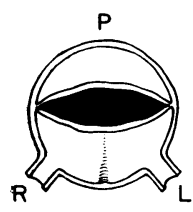

$36(72 \%)$

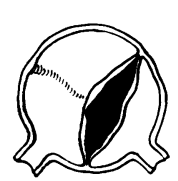

$13(26 \%)$

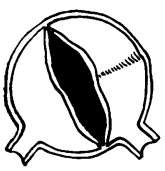

$1(2 \%)$
ACQUIRED
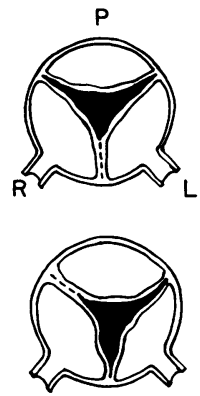

$12(24 \%)$
Fig. 2 Schematic diagram of location of raphe in 50 congenitally bicuspid aortic valves (left) and of commissural fusion in 50 acquired bicuspid aortic valves (right). $L$, left cusp; $P$, posterior cusp; $R$, right cusp.
In patients with either congenitally bicuspid or acquired bicuspid valves, the right and left aortic cusps were most commonly conjoined $(72 \%$ and $66 \%$, respectively) (Fig. 2 and Table). This non-random distribution was highly significant $\left(p<0.001 ; \chi^{2}\right.$ test) within each group but was not significant between groups.

In hearts with congenitally bicuspid aortic valves, the left coronary ostium arose at or above the sinotubular junction in 44 per cent (Fig. 3), but had similar origin in only 20 per cent of hearts with acquired bicuspid aortic valves $\left(p<0.02 ; \chi^{2}\right.$ test). The right coronary ostium arose at or above the aortic sinotubular junction in only 16 per cent of the congenital group and 14 per cent of the acquired group.

Of those cases with congenitally bicuspid aortic valves, the conus artery arose from the aorta in 31 per cent and from the proximal right coronary artery in the remainder. In the acquired group, the conus artery had aortic origin in 36 per cent and right coronary arterial origin in the remainder. With both groups combined, aortic origin of the cenus artery occurred in three of 20 cases (15\%) with left coronary dominance and in nine of 27 cases (33\%) with short $(<8 \mathrm{~mm})$ left main coronary artery.

In the congenital group, coronary arterial dominance included $32(64 \%)$ right, $13(26 \%)$ left, and five $(10 \%)$ shared, whereas the distribution in the acquired group was $40(80 \%)$ right, eight (16\%)

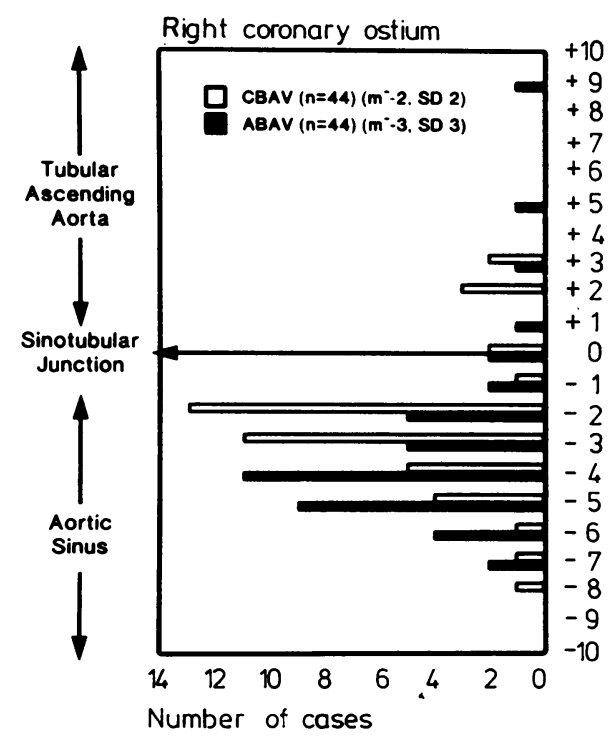

Fig. 3 Position of right and left coronary ostia relative to aortic sinotubular junction in cases of congenital: (CBAV) and acquired ( $A B A V)$ bicuspid aortic valves. m, mean; $n$, number; $S D$, standard deviation.

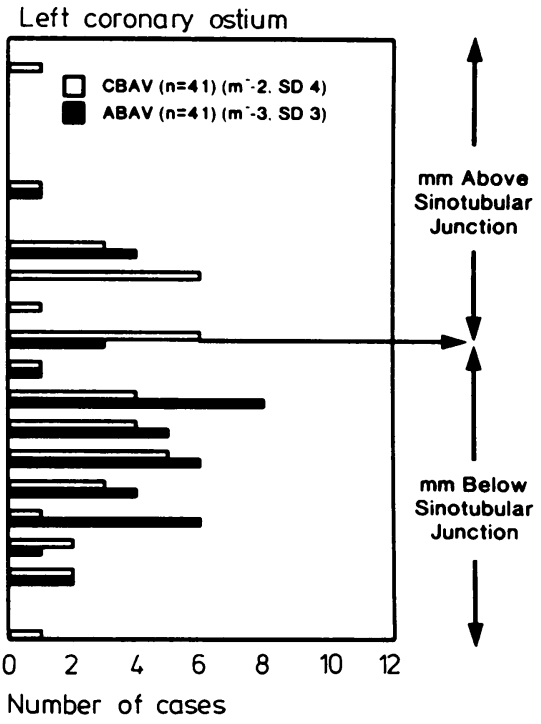




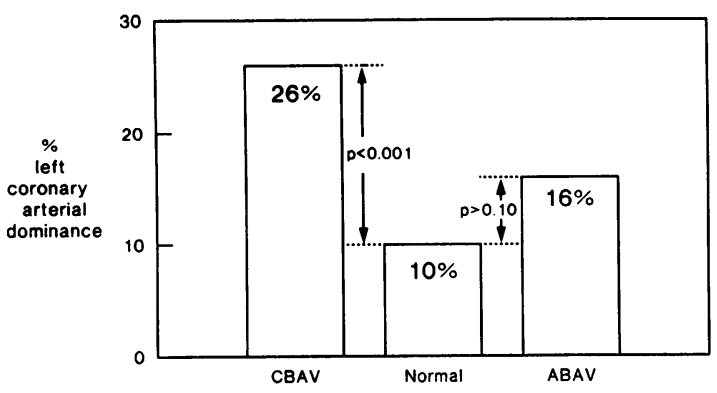

Fig. 4 Comparison of incidence of left coronary arterial dominance in normal population with patients with congenital (CBAV) and acquired ( $A B A V)$ bicuspid aortic valves.

left, and two (4\%) shared. In normal hearts, right coronary artery dominance has been reported in 70 per cent, left dominance in 10 per cent, and shared dominance in 20 per cent. ${ }^{2}$ When compared with the expected incidence of left dominance in normal hearts $(10 \%)$, the incidence in the congenital group $(26 \%)$ was significant $(p<0.001 ; z$ test $)$, while that in the acquired group $(16 \%)$ was not (Fig. 4).

In hearts with congenitally bicuspid aortic valves, the length of the left main coronary artery averaged $9.3 \mathrm{~mm}$ (range, 0 to $24 \mathrm{~mm}$ ). This length was not significantly different from that in hearts with acquired bicuspid aortic valves (mean, $10.3 \mathrm{~mm}$; range, 0 to $25 \mathrm{~mm}$ ). In the congenital group, the length of the left main coronary artery in 13 cases with left coronary dominance (mean, $6.3 \mathrm{~mm}$ ) was significantly shorter $(p<0.015$; Student's t test) than in the remaining 37 cases with right or shared dominance (mean, $10.3 \mathrm{~mm}$ ). Similarly, in the acquired group, the eight cases with left coronary dominance had shorter left main coronary arteries (mean, $7.5 \mathrm{~mm}$ ) than the remaining 42 cases (mean, $10.8 \mathrm{~mm}$ ), though this difference was not significant. With congenital and acquired groups combined, a short left main coronary artery $(<8 \mathrm{~mm})$ was present in 13 of 21 cases (62\%) with left coronary dominance and in only 16 of $79(20 \%)$ with right or shared coronary dominance $\left(p<0.001 ; \chi^{2}\right.$ test).

\section{Discussion}

Detailed knowledge of variations in coronary arterial distribution has been of great clinical importance in the medical and surgical management of patients with specific congenital or acquired cardiac disorders. ${ }^{15} 16$ In the present study, coronary distribution was assessed in necropsy specimens from 100 patients with bicuspid aortic valves. Some variations in coronary distribution depended on the aetiology of the aortic valve disease (congenital versus acquired), while other variations depended upon coronary arterial dominance (left versus right or shared), regardless of the underlying aetiology of the bicuspid aortic valve.

\section{BICUSPID AORTIC VALVE}

In both congenitally bicuspid and acquired bicuspid aortic valves, the common cusp usually involved the right and left cusps ( $72 \%$ and $66 \%$, respectively) (Fig. 2 and Table). The reason for this non-random distribution is unclear. Perhaps the shape of the left ventricular outflow tract causes more haemodynamic stress or trauma to the commissure between right and left cusps than to other regions of the aortic valve. A developmental defect may, in part, also dictate the location of the conjoined cusp in the congenital group. In the acquired group, the possibility exists that acquired disease may affect a congenitally bicuspid aortic valve ${ }^{17-20}$; this topic will be further discussed later.

\section{CALCIFICATION OF AORTIC VALVE}

The general finding of less calcification of congenitally bicuspid valves in the younger age group supports the assumption that the vast majority of congenitally bicuspid aortic valves function normally at birth and become stenotic with age, as calcification appears and becomes progressively more

Table Incidence of left coronary arterial dominance and of short left main coronary artery in bicuspid aortic valve

\begin{tabular}{|c|c|c|c|c|c|c|c|c|c|}
\hline \multirow{2}{*}{$\begin{array}{l}\text { Common } \\
\text { cusps }\end{array}$} & \multicolumn{3}{|c|}{$C B A V$} & \multicolumn{3}{|c|}{$A B A V$} & \multicolumn{3}{|c|}{$C B A V+A B A V$} \\
\hline & Total & $L$ dom & $S \operatorname{lm} a$ & Total & $L$ dom & $S \operatorname{lm} a$ & Total & $L$ dom & S lma \\
\hline
\end{tabular}

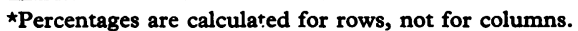

ABAV, acquired bicuspid aortic valve; CBAV, congenitally bicuspid aortic valve, L, left, L dom, left coronary dominance, P, posterior $R$, right, $S$ lma, short left main coronary artery, $<8 \mathrm{~mm}$. 
severe. ${ }^{12} 13$ The finding of mobile and only mildly calcified valves in some patients in the older age group indicates that the progression to calcific aortic stenosis does not occur at predictable rates or extents in individual patients.

\section{RIGHT AND LEFT CORONARY OSTIA}

In patients with congenitally bicuspid aortic valves, the left coronary ostium arose below the aortic sinotubular junction in only 56 per cent of cases (Fig. 3). In the normal population, the left coronary ostium arose below this junction in 70 per cent of cases reported by Vlodaver et al. ${ }^{21}$ and in 80 per cent of cases in the present study (acquired group). The right coronary ostium, arising below the sinotubular junction in 85 per cent of cases, was relatively constant in position in both the congenital and acquired groups. These data have practical application in coronary angiography, where the coronary ostia are generally considered to arise from the aortic sinuses, that is below the sinotubular junction.

\section{AORTIC ORIGIN OF CONUS CORONARY ARTERY}

In both groups, the conus coronary artery arose from the right aortic sinus in approximately onethird of cases and from the proximal right coronary artery in the remaining two-thirds. This is similar to the incidence of aortic origin of the conus artery reported by others ( 23 to $50 \%$ ). ${ }^{21-23}$

Our initial hypothesis was that a short or absent left main coronary artery probably resulted embryologically from partial or complete incorporation of the left main artery into the aortic sinus. If such were the case, then we expected there to be a similar incorporation of the proximal right coronary artery into the right aortic sinus, thereby resulting in a higher than anticipated incidence of aortic origin of the conus artery. Such was not the case.

In fact, the incidence of aortic origin of the conus artery in patients with short left main artery was 33 per cent (as expected) and in patients with left coronary dominance was 15 per cent (less than expected). Therefore, the embryological factors that influence aortic origin of the conus coronary artery appear to be independent of those that affect length of the left main coronary artery and coronary arterial dominance.

\section{CORONARY ARTERIAL DOMINANCE}

The incidence of left coronary dominance in patients with normal aortic valves has been reported to be 10 to 12 per cent. ${ }^{2}{ }^{4}$ Higgins and Wexler ${ }^{1}$ reported high incidences of left coronary dominance in patients with isolated aortic stenosis $(36 \%)$ and with congenitally bicuspid aortic valves (57\%).

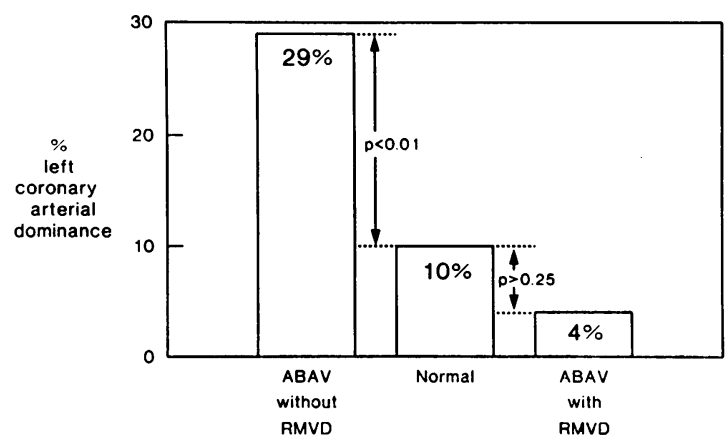

Fig. 5 Comparison of incidence of left coronary arterial dominance in normal population with cases of acquired bicuspid aortic valves ( $A B A V)$ with and without coexistent rheumatic mitral valvular disease (RMVD).

Other authors have reported lower figures both in patients with isolated aortic stenosis $(20 \text { to } 25 \%)^{23}$ and in those with congenitally bicuspid aortic valve (25 to $29 \%){ }^{2}{ }^{45}$ Our finding of left coronary dominance in 26 per cent of cases of congenitally bicuspid valves agrees quite well with that reported by these latter three authors (Fig. 4).

The incidence, however, of left coronary dominance in the acquired group $(16 \%)$ was much higher than the expected incidence of 10 per cent, as has been reported by Hutchins et al. ${ }^{2}$ not only in the normal population but also in patients with acquired bicuspid aortic valves. The reason for the high incidence in the present study may well represent more than chance variation. Some cases in the acquired group may represent acquired lesions involving atypical congenitally bicuspid aortic valves.

To test this hypothesis, the status of the mitral valve was carefully assessed in the acquired group; those hearts with rheumatic mitral valve disease would more likely have coexistent rheumatic aortic valve disease than congenital aortic valve disease. Of 26 specimens with rheumatic mitral valve disease, only one $(4 \%)$ had left coronary dominance. Of 24 hearts, however, with either normal mitral valves or non-rheumatic mitral valve disease, seven $(29 \%)$ had left coronary dominance (Fig. 5).

Some cases in this latter group may well represent acquired calcific stenosis of an atypical congenitally bicuspid aortic valve; the incidence of left coronary dominance $(29 \%)$ was much more similar to that of the congenital group $(26 \%)$ than to that of the normal population $(10 \%)$. When compared with the expected incidence of left coronary dominance in the normal population, the difference was highly significant $(p<0.01 ; z$ test). (Between the subgroups 
with and without rheumatic mitral valve disease, there was no significant difference i i location of the common aortic cusp, incidence of aortic origin of the conus coronary artery, or incidence of short $(<8 \mathrm{~mm})$ left main coronary artery.)

Recently, Waller et al. ${ }^{11}$ have described the anatomical spectrum of non-stenotic congenitally bicuspid aortic valves, some of which were atypical and had only partially conjoined cusps. Subsequent calcification could yield a valve almost indistinguishable from an acquired bicuspid aortic valve. Indeed, two reports have documented rheumatic aortic stenosis occurring in congenitally bicuspid aortic valves. ${ }^{18-20}$

LENGTH OF LEFT MAIN CORONARY ARTERY In normal hearts, the left main coronary artery is approximately $10 \mathrm{~mm}$ in length. ${ }^{78}$ Not only in normal hearts, however, ${ }^{6}$ but also in cases of aortic stenosis ${ }^{3}$ and in cases of congenitally bicuspid aortic valves, ${ }^{4}$ the left main coronary has been reported to be significantly shorter in patients with left coronary dominance than in those with right dominance. In the present study (both groups combined), the length of the left main coronary artery was substantially less in cases with left coronary dominance $(6.8 \mathrm{~mm})$ than in those with right or shared dominance $(10.6 \mathrm{~mm})$. Our findings support the concept that a short left main coronary artery is frequently associated with left coronary arterial dominance but is independent of diseases of the aortic valve, either congenital or acquired. ${ }^{36}$

We acknowledge Alice Langworthy and Duane $M$ Ilstrup, MS, Department of Medical Statistics and Epidemiology, Mayo Clinic and Foundation for their assistance in the statistical analysis of the data in this manuscript.

\section{References}

1 Higgins CB, Wexler L. Reversal of dominance of the coronary arterial system in isolated aortic stenosis and bicuspid aortic valve. Circulation 1975; 52: 292-6.

2 Hutchins GM, Nazarian IH, Bulkley BH. Association of left dominant coronary arterial system with congenital bicuspid aortic valve. Am $\mathcal{f}$ Cardiol 1978; 42: 57-9.

3 Murphy ES, Rösch J, Rahimtoola SH. Frequency and significance of coronary arterial dominance in isolated aortic stenosis. Am $\mathcal{f}$ Cardial 1977; 33: 505-9.

4 Johnson AD, Detwiler JH, Higgins CB. Left coronary artery anatomy in patients with bicuspid aortic valves. $B r$ Heart $\mathcal{f} 1978$; 40: 489-93.

5 Scholz DG, Lynch JA, Willerscheidt AB, Sharma RK, Edwards JE. Coronary arterial dominance associated with congenital bicuspid aortic valve,
Arch Pathol Lab Med 1980; 104: 417-8.

6 Kronzon I, Deutsch P, Glassman E. Length of the left main coronary artery. Its relation to the pattern of coronary arterial distribution. Am $\mathcal{F}$ Cardial 1974; 34: 787-9.

7 Green GE, Bernstein S, Reppert EH. The length of the left main coronary artery. Surgery 1967; 62: 1020-4.

8 Fox C, Davies MJ, Webb-Peploe MM. Length of left main coronary artery. $B r$ Heart $\mathcal{f} 1973 ; 35$ : 796-8.

9 Koletsky S. Congenital biscuspid aortic valves. Arch Intern Med 1941; 67: 129-56.

10 Koletsky S. Acquired bicuspid aortic valves. Arch Intern Med 1941; 67: 157-76.

11 Waller BF, Carter JB, Williams HJ Jr, Wang $\mathrm{K}$, Edwards JE. Bicuspid aortic valve. Comparison of congenital and acquired types. Circulation 1973; 48: $1140-50$.

12 Roberts WC. The congenitally bicuspid aortic valve. A study of 85 autopsy cases. Am $\mathcal{F}$ Cardiol 1970; 26: 72-83.

13 Fenoglio JJ Jr, McAllister HA Jr, DeCastro CM, Davia JE, Cheitlin MD. Congenital bicuspid aortic valve after age 20 . Am $\mathcal{F}$ Cardiol 1977; 39: 164-9.

14 Schlesinger MJ. Relation of anatomic pattern to pathologic conditions of the coronary arteries. Arch Pathol 1940; 30: 403-15.

15 Spencer FC, Malette W. Technical considerations of coronary perfusion during aortic valve replacement. f Cardiovasc Surg (Torino) 1968; 9: 562-72.

16 Furlong MB Jr, Gardner TJ, Gott VL, Hutchins GM. Myocardial infarction complicating coronary perfusion during open-heart surgery. $\mathcal{f}$ Thorac Cardiovasc Surg 1972; 63: 185-92.

17 Roberts WC. Anatomically isolated aortic valvular disease. The case against its being of rheumatic etiology. Am f Med 1970; 49: 151-9.

18 McReynolds RA, Ali N, Cuadra M, Roberts WC. Combined acute rheumatic fever and congenitally bicuspid aortic valve. A hitherto unconfirmed combination. Chest 1976; 70: 98-100.

19 Wanderman KL, Gueron M. Coexistence of congenital bicuspid aortic valve and rheumatic heart disease (letter). Chest 1977; 71: 562.

20 Borman JB, Appelbaum A, Hirsch M, Wanderman KL, Gueron M. Quadruple valve commissurotomy. f Thorac Cardiovasc Surg 1975; 70: 712-6.

21 Vlodaver Z, Neufeld HN, Edwards JE. Coronary arterial variations in the normal heart and in congenital heart disease, New York: Academic Press, 1975: 15-17, 19, \& 20.

22 Schlesinger MJ, Zoll PM, Wessler S. The conus artery: a third coronary artery. Am Heart $\mathcal{F} 1949$; 38: 823-36.

23 Baroldi G, Scomazzoni G. Coronary circulation in the normal and the pathologic heart. Washington DC: Armed Forces Institute of Pathology, 1967: 25.

Requests for reprints to Dr William D Edwards, Department of Pathology and Anatomy, Mayo Clinic, Rochester, Minnẹsota 55901, USA, 